\title{
Wear behavior of a bio-inspired bearing for off-center loads
}

\author{
Sysaykeo Delphine ${ }^{12 *}$, Linares Jean-Marc ${ }^{1}$, Mermoz Emmanuel ${ }^{12}$ \\ 1. Bio-inspired design Laboratory, Aix-Marseille universite, 13100 Aix-en-Provence, France \\ 2. Advanced concepts and Dynamic systems architecture department, Airbus Helicopters, Aeroport \\ International Marseille Provence, 13700 Marignane, France
}

\begin{abstract}
Misalignment is one of the most common causes of wear in bush bearings. Design improvements have been proposed by research studies for years. Unfortunately, it did not efficiently reduce the phenomenon. Classic geometrical designs sometimes reach their limits. For this reason, a bio-inspired design is proposed to solve the impediment. In this article, a bio-inspired bearing suited to misalignment was tested and compared to a classical bush bearing. The contact pressures of both bearings were compared with static finite element simulations for off-center load. Due to the complex shape of the involved contact, the performances of both bearings were also studied over time. Their wear behaviors were predicted with a numerical method. The methodologies emplaced to simulate the wear are described in this paper. Particularly, the wear coefficient determination obtained by experimental testing is detailed. The results for the classical bearing are in accordance with the literature. The pressure value, the contact zone and the wear depth are compared and discussed. Although the pressure is not uniformly distributed over the bio-inspired bearing, the simulations show a deeper wear on the classical bush bearing than on the bio-inspired bearing. Therefore, the superiority of this bearing is proved.
\end{abstract}

Keywords: Biologically inspired design, Bush bearing, Wear, Simulation

\section{Introduction}

The service life of a mechanism is strongly related to the wear that occurs on its links. Bush bearings have a widespread use in mechanisms. One of the most common causes of wear in the bearing is misalignment between the shaft and the outer ring. The wear effect of misalignment occurs when [1]: asymmetric load is applied; the shaft or the outer ring are distorted; defaults of clearance appears after manufacturing.

It has been noticed that misalignment induces a greater maximum pressure compared to aligned cases. The pressure peak moves towards the bearing edges. An extensive review dealing with misalignment was made by Jang et al. [1]. The clearance is strongly related to the misalignment and has a huge impact on bush bearing performances [2]. This clearance can be reduced in order to enhance the performance of the link. However, the manufacturing cost

*Corresponding author:

Sysaykeo Delphine

E-mail: delphine.sysaykeo@etu.univ-amu.fr 
would increase significantly [3]. The design of the bush bearing is a trade-off between tolerance specifications and manufacturing costs.

Research studies have been realized in order to reduce the negative impact of misalignment on the wear. For example, Colbert et al. show that it is useful to have a radius on bearing edges rather than a chamfer [4]. Strzelecki demonstrates the mechanical performance of a hydrostatic bush bearing, in which the outer ring has a hyperboloidal profile [5]. However, in our paper, the studied bearing is lubricated with grease and its rotational speed is quite low. Thus, such design improvements were not applicable or not sufficient to reduce efficiently the wear phenomenon for this case. Classic mechanical designs sometimes reach their limits and for that reason, bio-inspiration is a new research path. Bio-inspiration gives a new vision on mechanics and leads to infinite inspirations. This is "the use and integration of biological and bio-inspired principles" [6] to solve technical issue. Some key papers representing this bioinspiration can be cited: Liu et al. [7] make a review on bio-inspired multiscale functions; Malshe et al. [8] gather some bio-inspired advanced functional surfaces; Porter et al. [9] propose a keynote on bio-inspired articulated structures. In particular, the study of biological joints opens new possibilities for the design of innovative mechanical links. For example, Vertechy et al. propose a new two degrees of freedom spherical mechanism inspired by animal's knee joint [10]. This new articulation is compared with traditional mechanisms and it appears to be stronger, lighter, faster, and more accurate. Porter mimics the seahorse tail structure for a flexible armor application. Its tail has indeed the capacity to be compressed up to $50 \%$ while protecting the vertebrae from fracture [11]. The inspiration from biological joints seems therefore relevant to the design of a new mechanical link adapted to misalignment. 
The purpose of this paper is to model and analyze the wear behavior of a bio-inspired bearing designed to undergo asymmetric loading. This bearing inspired from the lamb elbow could replace bush bearings in specific industrial mechanisms. First, the contact pressure of this bearing will be analyzed for a static case and compared with the classical bush bearing. The contact area of this bio-inspired bearing is a complex shape. For that reason, the evolution of the contact area and the contact pressure over time cannot be easily anticipated. Therefore, in a second part, the wear behavior of the bio-inspired bearing will be predicted and compared with the classical bush bearing. For that, wear simulation method using the Archard law will be performed. This method has shown good wear predictions in literature thanks to iterations of static simulations [12 - 18]. To the best of our knowledge, this method has never been used for complex shape such as the bio-inspired bearing.

\section{Materials and methods}

\subsection{Static behavior of both bearings for off-center load}

In this section, the contact pressure distribution of a bio-inspired bearing is compared to a classical bush bearing for a static off-center load using finite element (FE) simulations. First, the geometry of the studied bearings is introduced, then the finite element model is detailed and results are presented.

\subsubsection{Bio-inspired bearing description}

The joint of interest was the elbow, which is composed of the humerus, the radius and the ulna. For quadruped mammals, radius and ulna are joined by a small but thick and resistant ligament which allows only a small range of movement [19]. Their elbow joints are thus a ginglymoid system which, in the field of mechanics, is comparable to a pivot connection. 
In this paper, the source of inspiration for the design of a bio-inspired bearing was the lamb elbow. Firstly, the lamb was chosen as a member of unguligrade quadruped animal as it can bear high mechanical stresses [20]. Secondly, lamb parts are particularly easy to obtain for analysis purposes. Thirdly, studies show that the kinematics of its elbows are similar to a pivot link [20,21]. Besides, its humerus is comparable to a revolution shape which facilitates its mimicking. Finally, the link is asymmetric since it undergoes off-center load (Fig. 1.a). The legs are indeed off-center in reference to the direction of the animal weight. Its application for mechanisms under asymmetric load is thus relevant.

The bio-inspired bearing proposed for the study has been developed in a previous work [22]. The bearing was inspired from the articular surfaces of the lamb elbow that was scanned (Fig. 1.b, Fig. 1.c, Fig. 1.d). The humerus cartilage was easier to mimic since it has revolution shape. Its profile was smoothed to design the bio-inspired bearing shown in Fig. 1.e. The bearing is composed of 3 contact zones and their profiles are approximated by 3 polynomials of degree 2. For off-center load, the shaft and the outer ring are in contact on the left and right parts of the bearing. The center part of the bearing is dedicated to support axial load. The gap between the shaft and the outer ring is defined with a normal clearance specification with a value of $0.12 \mathrm{~mm}$. For this study application case, the bio-inspired bearing is $34.5 \mathrm{~mm}$ in length $(L)$ and has a maximum radius of $14.5 \mathrm{~mm}(R 2)$ (see on the left of Fig. 2). The radial dimensions of the bearing are different along the axis and vary from $11.5 \mathrm{~mm}(R 1)$ to $14.5 \mathrm{~mm}(R 2)(\Delta R=$ $3 \mathrm{~mm}$ ). A radius of $0.5 \mathrm{~mm}$ is applied on the external edges of the bearing. The bearing undergoes off-center load of $F=550 \mathrm{~N}$ applied at $L 1=93 \mathrm{~mm}$ from its center. All dimensions are defined for potential future case study. 
The radius of the classical bush bearing is the mean value of the bio-inspired bearing's radius, which is $13 \mathrm{~mm}(R 3)$ (Fig. 2). The dimension of the classical bush bearing is $34.5 \mathrm{~mm}$ in length so that it has a size comparable to the bio-inspired bearing.

\subsubsection{Bio-inspired and classical bush bearings comparison for a static off-center load}

The finite element modeling was performed in Simcenter V12 software. Both bearings were meshed with hexahedral elements. The contact zones of both bearings were more finely meshed (side dimensions $0.25 \mathrm{~mm}$ ). The load $F$ was applied via 1D rigid body elements (see Fig. 2). All the degrees of translation have been deleted and only the tilt of the shaft was kept free. The outer rings were embedded. The outer ring material was $\mathrm{Cu} \mathrm{Sn} 10 \mathrm{~Pb} 10\left(E_{1}=75000\right.$ $\mathrm{MPa}$ and $\left.v_{1}=0.3\right)$. The shaft material was $100 \mathrm{Cr} 6\left(E_{2}=205000 \mathrm{MPa}\right.$ and $\left.v_{2}=0.3\right)$. The computations were performed by the solver Samcef Mecano which runs non-linear static computations. This finite element modeling will be used for the static study case and for the wear simulation process.

Fig. 3 shows the contact pressure distribution for the classical bush bearing and the bio-inspired bearing. On the classical bush bearing, the contact zones are located near the edges, in a very restricted area and with elongated forms. This shape was also observed by Schmidt et al. [18] who described it as being linear. The calculated maximum contact pressure is $143 \mathrm{MPa}$. On the bio-inspired bearing, the contact areas are wider with an elliptic form. The maximum contact pressure is $55 \mathrm{MPa}$. The pressure zones are at a greater distance from the bearing edges than in the cylindrical bearing. The bio-inspired design enables a reduction of the over-pressure observed in the classical bush bearing.

For a static situation, the bio-inspired bearing gives much better performances than the classical bush bearing. However, study [18] shows that the contact areas of the cylindrical bush 
bearing grow from a line shape to a parabola shape when the wear process occurs. This leads to the question of how the bio-inspired bearing contact zones will evolve. The bio-inspired bearing has indeed a complex shape with elliptic contact zones in the studied static case. The evolution of the area of the contact zones and the wear behavior of the bio-inspired bearing during its lifetime are not easily predictable. The aim of this study is to predict the performances of the bio-inspired bearing, in terms of area of contact zones, contact pressure value and wear depth.

\subsection{Wear simulation model}

The use of wear laws is helpful to predict mechanical systems' behavior during their service lives. The well-known Archard law has proved to give good wear estimations. It predicts the removed wear volume of a solid sliding against another. Since the 2000s, a wear simulation method has been employed using this Archard law to predict the wear. This section will start with the Archard law definition then the wear simulation method will be presented. The workflow of this method will be described. In particular, the wear coefficient derived from the Archard law will be experimentally obtained.

\subsubsection{Archard wear theory}

In the Archard law, the wear volume $\Delta V o l$ is proportional to the applied normal load $F$ and the sliding distance $\Delta s$. It can be expressed as follows:

$$
\Delta V o l=\frac{K r \cdot F \cdot \Delta s}{H} \quad\left[\mathrm{~mm}^{3}\right]=\frac{[][N][\mathrm{mm}]}{\left[\frac{\mathrm{N}}{\mathrm{mm}^{2}}\right]}
$$

where $\Delta \mathrm{Vol}$ is the wear volume; $K r$ is a dimensionless wear coefficient; $F$ is the applied normal load, $H$ is the hardness of the worn material; $\Delta s$ is the sliding distance. 
This law is applicable between "two bodies" where an abrasion phenomenon occurs. In consequence, it means that the rubble particles (the third body) are not considered since they are not trapped in the interface. As the materials of the two parts are considered to be homogenous, it is not applicable for hardened or superficially treated materials. It is not appropriate either for hydrodynamic or mixed lubrication regimes since the degradation of the lubricant can change the wear rate. In our study case, the outer rings were made of $\mathrm{Cu} \mathrm{Sn} 10 \mathrm{~Pb}$ 10 whereas the inner rings were made of $100 \mathrm{Cr} 6$. The outer ring material was significantly softer than the inner ring material. Since the wear rate of a soft solid is greater than that of a hard solid, the wear is mainly located on the outer ring. In this study, only the wear of the outer rings will be considered.

For the research's interest, this global law can be modified to be applied locally in order to estimate the wear depth $[13,14][16,17]$. If the hardness for a solid is constant, a new wear coefficient can be defined as $K=K r / H$ with the dimension of $\left[\mathrm{mm}^{2} / \mathrm{N}\right]$. By dividing both sides of Eq. (1) by the contact area $\Delta A$, the wear volume becomes the wear depth $\Delta h=\Delta V / \Delta A$ and the applied normal load becomes the applied pressure $P=F / \Delta A$. The sliding distance $\Delta s$ can be defined as the sliding velocity $V$ multiplied by a time $\Delta t$. Eq. (1) becomes:

$$
\Delta h=K . P . V . \Delta t \quad[\mathrm{~mm}]=\left[\frac{\mathrm{mm}^{2}}{\mathrm{~N}}\right]\left[\frac{\mathrm{N}}{\mathrm{mm}^{2}}\right][\mathrm{mm} / \mathrm{s}][\mathrm{s}]
$$

\subsubsection{Wear simulation method}

The workflow of the wear simulation method is presented in Fig. 4. It is composed of a loop of FE simulations which is represented in red in Fig. 4. Before starting the simulation process, setup conditions must be defined in the blue box. The values of the setup conditions are calculated on the base of beforehand activities shown in the purple box.

*Corresponding author:

Sysaykeo Delphine

E-mail: delphine.sysaykeo@etu.univ-amu.fr 
In the wear simulation loop, each iteration corresponds to the removal of material, due to wear, from the outer ring of the bearing. The material loss is realized through the displacement of the nodes belonging to the contact area. The process starts with a static simulation. Then the contact pressure per node is retrieved. This allows the calculation of the displacement value for each node between two iterations, corresponding to the wear depth. The wear depth value is calculated following Eq. (2): $\Delta h=K . P . V . \Delta t$. In this equation, only the contact pressure result changes between iterations. The wear coefficient $K$ and the sliding velocity $V$ are setup conditions defined and calculated below.

In this static simulation model, a friction coefficient was not applied since grease was used in the bearings, therefore the resultant direction of the reaction forces corresponds to the pressure direction. After each static simulation, the reaction force per node was retrieved to calculate the relative displacement along $\mathrm{X}, \mathrm{Y}$ and $\mathrm{Z}$ for each node label.

One iteration of the wear simulation loop could represent one turn of the bearing shaft, but this would lead to a huge number of simulations. A well-known technique to saves time and digital resources is to have a maximum wear depth allowed between each iteration (Hmax) [16]. For a same Hmax between iteration, the number of feasible cycles between two iterations increases during the wear process. This is due to the expansion of the contact area during wear process and the decrease of the contact pressure value. The number of cycles between two iterations is thus not constant during the process but it will rise. This technique is appropriate for complex contact shapes such as curved surfaces [13]. The number of realized cycles is calculated at each iteration. The setting of Hmax will be described in the next section.

After each simulation, the maximum wear of all nodes induced by one turn of shaft rotation is calculated. Then the maximum possible number of turns is calculated so that the wear per 
node does not exceed the Hmax value. This number of turns corresponds to the additional turns made between this iteration and the next one. The accumulative wear per node is then calculated.

Two phases during the wear process can be highlighted as observed by [14]: the initial wear stage with a sharp increase of the wear depth per turn; then the stable wear stage where the wear depth per turn is linear. Thus, from this second wear stage, the wear depth can be anticipated. When the stable wear stage has been reached, the iteration process stops.

\subsubsection{Simulation setup}

Before starting the simulation iterations, three setup constants were calculated through preliminary activities (see the purple box in Fig. 4): the sliding velocity, the maximum wear depth per iteration and the wear coefficient. They are detailed below.

\subsubsection{Sliding velocity}

The sliding velocity $(V)$ for each node was considered constant during wear. The sliding velocity per node is the rotation speed of the shaft (100 rpm in this study) multiplied by its distance to the axis. The displacement of the node induced by the wear was really small compared to the distance between the rotation axis and the node (about $15 \mu \mathrm{m}$ compared to a radius of $13 \mathrm{~mm}$ ). In the cylindrical bush bearing, the sliding velocity was $8160 \mathrm{~mm} / \mathrm{min}$. However, in the bio-inspired bearing, the radius was not the same for each node. The sliding velocity varied then from $7200 \mathrm{~mm} / \mathrm{min}$ to $9120 \mathrm{~mm} / \mathrm{min}$. This represents a $26 \%$ difference. All the distances and corresponding sliding velocities were calculated through the collect of mesh data before starting the simulation iterations.

\subsubsection{Maximum wear depth}


The maximum wear depth allowed between two iterations (Hmax) is dependent on the design of the case study, namely the geometry and the loading [13]. It was defined as constant during the process and should be the highest possible. However, if the node displacement is too important, the contact between the two surfaces can disappear. The pressure distribution becomes coarse and wrong. In our study, short simulation test runs were made to adjust the Hmax value, as performed in Podra work [16]. The Hmax's adjustment was established using the bio-inspired bearing case, which has a more complex contact geometry than the cylindrical bush bearing. The Hmax parameter was defined identical for both bearing to avoid biased comparisons. This Hmax value was of course tested and verified on the cylindrical bush bearing. Following a few FE simulations, the Hmax value was fixed at $0.72 \mu \mathrm{m}$.

\subsubsection{Experimental wear coefficient determination}

Studies show that the wear coefficient depends on the two materials in contact but also on the sliding velocity and the pressure value [14]. For each case study, the wear coefficient must thus be tested. Pin-on-plate tests were realized to determine the wear coefficient. This method has been followed by Podra's et al. work [16]. Tests were realized for three different sliding velocities $(V)$ and three different pressures for a total of 9 tests (see Table 1). In the previous section, the maximal contact pressure for the bio-inspired bearing was shown to be $55 \mathrm{MPa}$. Tests were carried out plus or minus $5 \mathrm{MPa}$ from this value, namely $50 \mathrm{MPa}$ and $60 \mathrm{MPa}$.

The pin material was $\mathrm{Cu} \mathrm{Sn} 10 \mathrm{~Pb} 10$ which corresponds to the outer bearing material. The pin was a cylinder of $20 \mathrm{~mm}$ in diameter with a machined sphere with a $400 \mathrm{~mm}$ diameter at its extremity. The sphere was following a circular path on a plate of $100 \mathrm{Cr} 6$, which corresponds to the shaft material. The pin covered a path of $78535 \mathrm{~mm}(\Delta s)$ on the plate, which corresponds to 500 turns on a circle with a radius of $25 \mathrm{~mm}$. In some studies, the wear is 
quantified by mass loss [12][13]. In our study, the wear was quantified by the volume loss. After each test, the volume loss could be calculated using the wear depth $d_{i}$ measured on the worn sphere profile, with $i$ varying from 1 to 9 .

Profiles of the worn pin were measured with an optical chromatic confocal sensor instrument with a resolution of 0.04 micrometers. Once the wear depths were obtained for each of the 9 tests, the volume loss per test was $\left(\Delta V o l_{i}\right)$ calculated and the wear coefficients $K_{i}$ could be calculated, with $i$ varying from 1 to 9 :

$$
K_{i}=\frac{\Delta \operatorname{Vol}_{i}}{\Delta s F_{i}} \quad\left[\frac{\mathrm{mm}^{2}}{\mathrm{~N}}\right]=\frac{\left[\mathrm{mm}^{3}\right]}{[\mathrm{mm}][\mathrm{N}]}
$$

where: $\Delta s$ is the covered distance, which is the same for all tests $(78535 \mathrm{~mm}) ; \Delta V o l_{i}$ is the volume loss per test; $F_{i}$ is the applied load on the pin per test. The wear coefficients $K_{i}$ were calculated as shown in Table 1. A parametric plan, introduced in Eq. (4), was calculated to fit with the wear coefficients results:

$$
K_{i}=P_{i} \alpha-V_{i} \beta+\omega
$$

where $K_{i}$ corresponds to the wear coefficient value for the test number $i, P_{i}$ corresponds to the pressure value for the test number $i ; V_{i}$ corresponds to the sliding velocity value for the test number $i ; \alpha$ tilts the plan around the $\mathrm{P}$-axis and $\beta$ tilts the plan around the $\mathrm{V}$-axis. The plan is located at a height of $\omega$. The $\alpha$ angle value corresponds to the influence of the sliding velocity on the wear coefficient. In the same way, $\beta$ value is the influence of the pressure on the wear coefficient. After best fitting using the least square method, $\alpha$ was -1.79 E-11 (radian) and $\beta$ was $-1.76 \mathrm{E}-13$ (radian). The value of $\omega$ was $5.81 \mathrm{E}-10$. Theses angle values were low. The estimated wear coefficient $K$ was calculated for each FE simulation using Eq. (4). 


\section{Results}

Results are presented for the classical and the bio-inspired bearings. The results are compared and improvements on the bio-inspired bearing are highlighted.

\subsection{Simulation results of classical bush bearing model}

The wear simulation was performed on the classical bush bearing. It was stopped after 15 000 turns because the wear was in the stable stage (linear wear). This was simulated by 40 iterations of the loop. Fig. 5 represents the behavior of the wear depth along 4 different paths, displayed on the bottom of Fig. 6 . The path 1 and the path 3 correspond to the evolution of the wear depth along the X-axis. The path 2 and the path 4 correspond to the evolution of the wear depth along the Y-axis in the most extensive wear zone. The wear depth was observed at 3 steps: 5 000, 10000 and 15000 turns. For each given step, the wear depth was more severe on the loaded side. Comparing the relative wear depths between the steps, the wear depth per turn was declining.

Along the paths 1 and 3, the wear depth is linear in respect to the $\mathrm{X}$ coordinates. This phenomenon was observed in Schmidt et al. work [18]. Meanwhile in paths 2 and 4, the wear produces a parabolic shape along the Y-axis, which was also observed in Schmidt work. The maximum wear depth observed on the classical bush bearing after 15000 turns is 23 micrometers on the right side and 25 micrometers on the left side.

The growth of the contact pressure distribution during iterations is shown in Fig. 6. The wear zone grows and becomes like a parabola since the wear grows non-linearly in both $\mathrm{X}$ and $\mathrm{Y}$ axes [18]. The maximum contact pressure value decreases at $26 \mathrm{MPa}$ for the left side and 19 MPa for the right side. 


\subsection{Simulation results of bio-inspired bush bearing model}

The wear simulation was then performed on the bio-inspired bearing for the same number of turns (15 000 turns), which represents 25 iterations of the loop. As shown above for the classical bush bearing, the wear depth on the bio-inspired bearing is presented in Fig. 7 on 4 paths displayed on the bottom of Fig. 8. Along the paths 1 and 3, the wear depth is nonlinear in respect to $\mathrm{X}$ coordinates, and the maximum is not at the edge like in the classical bush bearing. Along the paths 2 and 4, the wear depth forms a parabolic shape along the Y-axis like in the classical bearing. In the bio-inspired bearing, the wear depth was less severe on the loaded side. The maximum wear depth observed on the bio-inspired bearing after 15000 turns is 9 micrometers on the left side and 15 micrometers on the right side.

The evolution of the pressure distribution on the bio-inspired bearing during iterations is shown in Fig. 8. The shape of the wear area is more complex to describe. On the left side, the contact area looks like the bottom of a water drop. The contact area is stopped by the left edge. On the right side, the contact area is stopped by two edges after 15000 turns. The maximum pressure value is $11 \mathrm{MPa}$ for the left side and $26 \mathrm{MPa}$ for the right side.

\section{Discussion}

\subsection{Bio-inspired and classical bush bearing design comparison}

Fig. 9.a represents the maximum wear depth observed on the bearings during the simulation cycles. The wear depth per turn was much greater on the classical bush bearing at the beginning of the process. The reason is that the contact zones were small and located near the edges, which induced a high pressure and then a deeper wear. In both studied cases, the representative curve is decomposed into two parts: one stage with a great wear depth per turn

*Corresponding author:

Sysaykeo Delphine

E-mail: delphine.sysaykeo@etu.univ-amu.fr 
(it represents the classical run-in time phase), and one linear stage with smaller wear depth per turn.

The maximum contact pressure on the classical bearing drops considerably, see Fig. 9.b. The duration of run-in time of the classical bearing (around 6000 turns) is longer than that of the bio-inspired bearing (around 3000 turns). After these run-in times, the maximum contact pressure is equivalent on both bearings. The maximum contact pressure on the bio-inspired bearing decreases but less in proportion than on the classical bush bearing, although the number of nodes in contact is increasing and far exceeds that of the classical bush bearing, see Fig. 9.c .The contact zone on the left side of the bio-inspired bearing is indeed growing very fast compared to the right side. The pressure is not uniformly distributed over the bearing. At the end of the 15000 turns, the maximum contact pressure shows a difference of $15 \mathrm{MPa}$ between the left and right sides of the bio-inspired bearing and $7 \mathrm{MPa}$ for the classical bush bearing. The maximum contact pressure on the conventional bearing is on the loading side. On the contrary, it is located on the opposite side for the bio-inspired bearing. The reason for this is that the surface curvatures are smaller on the left side and induce a smaller contact area.

The most important point to note is that the maximum wear depth is 25 micrometers for the classical bush bearing against 15 micrometers for the bio-inspired bearing. Therefore, the superiority of this bearing is proved.

\subsection{Discussion on design improvement}

As a result of the wear simulation process, it is noted that the right side of the bio-inspired bearing was more quickly worn since the pressure was asymmetrically distributed from the start. The surface curvatures were too small and induced a high pressure. Besides, the contact 
zones were centered at the beginning but had widened during the wear process. They were thus touching the edges which lead to overpressure. It also stopped the progress of the contact area which induced a deeper wear. Furthermore, the potential contact area of the right side of the bearing was too reduced. The wear zone could not expand in left and right directions.

Thus, the areas for improvement of the bio-inspired pivot are: the modification of the bearing edge; the increase of the curvature of the right side surface; the enlargement of the right side; the readjustment of the contact zones with the center of the surfaces.

\section{Conclusion}

Bio-inspiration is a new research path which gives a new vision on mechanical design. A bio-inspired bearing designed to be adapted to misalignment was tested and compared to a classical bush bearing. Both bearings were compared with static finite element simulations for off-center load. The results show lower pressures for the bio-inspired bearing and a contact zone with an elliptic shape. This distinctive shape combined with the complex geometry of the bio-inspired bearing raise the question of how this contact zone evolves in time. The performance of the bio-inspired bearing, in terms of contact zones, contact pressure value and wear depth was predicted. The results were compared to the performance of the classical bush bearing. A numerical method using the Archard law was achieved. The results for the classical bearing are in accordance with the literature. The simulations show a deeper wear on the classical bush bearing than on the bio-inspired bearing. This leads to a longer period of service life for the bio-inspired bearing.

\section{Acknowledgments}


This work was supported by Airbus Helicopters and Aix-Marseille University. The experimental devices were founded by: European Community, French Ministry of Research and Education and Aix-Marseille Conurbation Community.

\section{References}

[1] Jang, J. Y., \& Khonsari, M. M. On the characteristics of misaligned journal bearings. Lubricants, 2015, 3(1), 27-53.

[2] Marques, F., Isaac, F., Dourado, N., \& Flores, P. An enhanced formulation to model spatial revolute joints with radial and axial clearances. Mechanism and Machine Theory, 2017, 116, 123-144.

[3] Cavalieri, F. J., \& Cardona, A. Non-smooth model of a frictionless and dry threedimensional revolute joint with clearance for multibody system dynamics. Mechanism and Machine Theory, 2018, 121, 335-354.

[4] Colbert, R. S., Alvarez, L. A., Hamilton, M. A., Steffens, J. G., Ziegert, J. C., Burris, D. L., \& Sawyer, W. G. Edges, clearances, and wear: Little things that make big differences in bushing friction. Wear, 2010, 268(1-2), 41-49.

[5] Strzelecki, S. Operating characteristics of heavy loaded cylindrical journal bearing with variable axial profile. Materials Research, 2005, 8(4), 481-486.

[6] Byrne, G., Dimitrov, D., Monostori, L., Teti, R., van Houten, F., \& Wertheim, R. Biologicalisation: Biological transformation in manufacturing. CIRP Journal of Manufacturing Science and Technology, 2018, 21, 1-32.

[7] Liu, K., \& Jiang, L. Bio-inspired design of multiscale structures for function integration. Nano Today, 2011, 6(2), 155-175.

[8] Malshe, A., Rajurkar, K., Samant, A., Hansen, H. N., Bapat, S., \& Jiang, W. Bio-inspired functional surfaces for advanced applications. CIRP Annals, 2013, 62(2), 607-628.

[9] Porter, M. M., Ravikumar, N., Barthelat, F., \& Martini, R. 3D-printing and mechanics of bio-inspired articulated and multi-material structures. Journal of the mechanical behavior of biomedical materials, 2017, 73, 114-126.

[10] Vertechy, R., Parenti-Castelli, V., \& Menon, C. Biologically inspired joints for innovative articulations concepts. ESA: Bologna, Italy, 2005.

[11] Porter, M. M., Novitskaya, E., Castro-Ceseña, A. B., Meyers, M. A., \& McKittrick, J. Highly deformable bones: unusual deformation mechanisms of seahorse armor. Acta biomaterialia, 2013, 9(6), 6763-6770.

[12] Kim, N. H., Won, D., Burris, D., Holtkamp, B., Gessel, G. R., Swanson, P., \& Sawyer, W. G. Finite element analysis and experiments of metal/metal wear in oscillatory contacts. Wear, 2005, 258(11-12), 1787-1793.

[13] Rezaei, A., Van Paepegem, W., De Baets, P., Ost, W., \& Degrieck, J. Adaptive finite element simulation of wear evolution in radial sliding bearings. Wear, 2012, 296(1-2), 660-671. [14] Xue, Y., Chen, J., Guo, S., Meng, Q., \& Luo, J. Finite element simulation and experimental test of the wear behavior for self-lubricating spherical plain bearings. Friction, 2018, 6(3), 297 306.

[15] Öqvist, M. Numerical simulations of mild wear using updated geometry with different step size approaches. Wear, 2001, 249(1-2), 6-11. 
[16] Podra, P., \& Andersson, S. Simulating sliding wear with finite element method. Tribology international, 1999, 32(2), 71-81.

[17] Mukras, S., Kim, N. H., Sawyer, W. G., Jackson, D. B., \& Bergquist, L. W. Numerical integration schemes and parallel computation for wear prediction using finite element method. Wear, 2009, 266(7-8), 822-831.

[18] Schmidt, A. A., Schmidt, T., Grabherr, O., \& Bartel, D. Transient wear simulation based on three-dimensional finite element analysis for a dry running tilted shaft-bushing bearing. Wear, 2018, 408, 171-179.

[19] M., Assabah, B., Bégin, M., Laemmel, E., Dos Santos, A., \& Crézé, M. Pronation and supination of the hand: anatomy and biomechanics. Hand Surgery and Rehabilitation, 2017, 36(1), 2-11.

[20] Poncery, B., Arroyave-Tobón, S., Picault, E., \& Linares, J. M. Effects of realistic sheep elbow kinematics in inverse dynamic simulation. PloS one, 2019, 14(3).

[21] Picault, E., Mermoz, E., Thouveny, T., \& Linares, J. M. Smart pressure distribution estimation in biological joints for mechanical bio-inspired design. CIRP Annals, 2018, 67(1), 153-156.

[22] Sysaykeo, D., Mermoz, E., \& Thouveny, T. Clearance and design optimization of bioinspired bearings under off-center load. CIRP Annals, 2020 


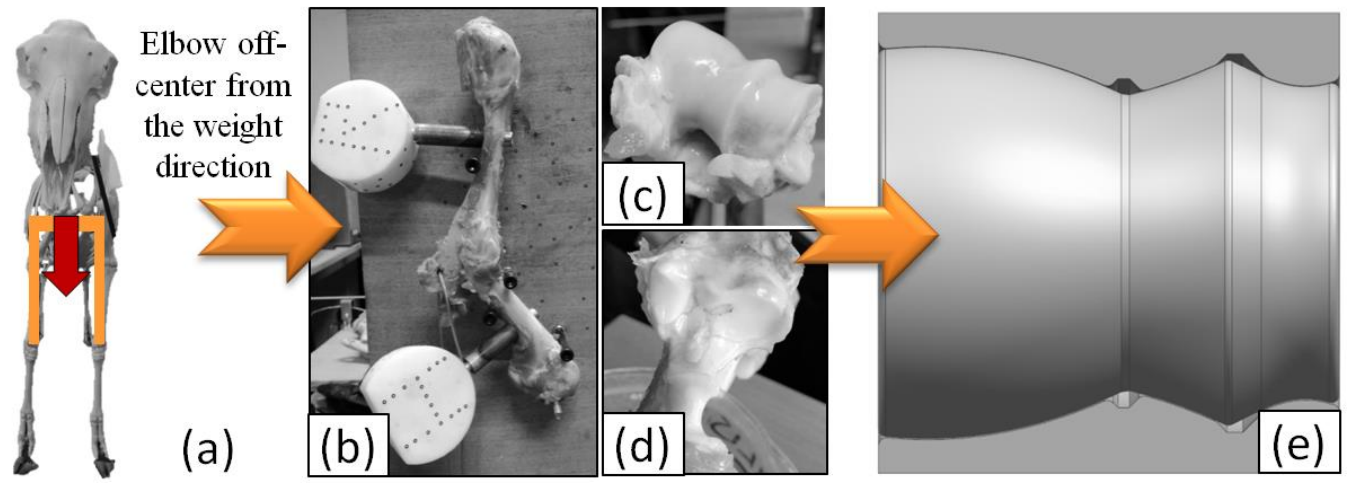

Fig. 1 : Bio-inspiration processes. (a) Off-center load on the lamb elbow (b) Lamb elbow (c) Humerus cartilage (d) Radius cartilage (e) Bio-inspired bearing 


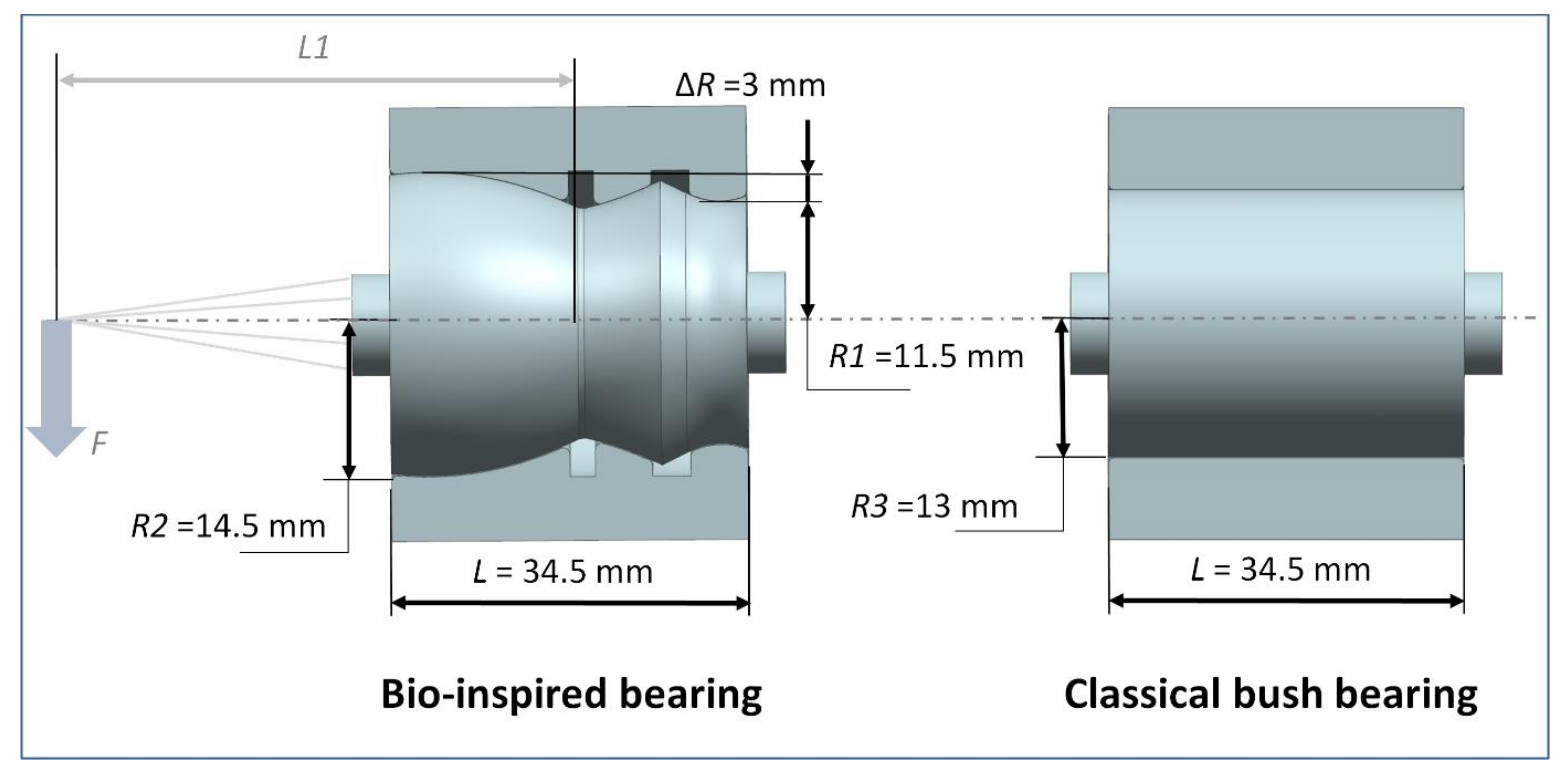

Fig. 2: Bio-inspired and classical bearings dimensions 


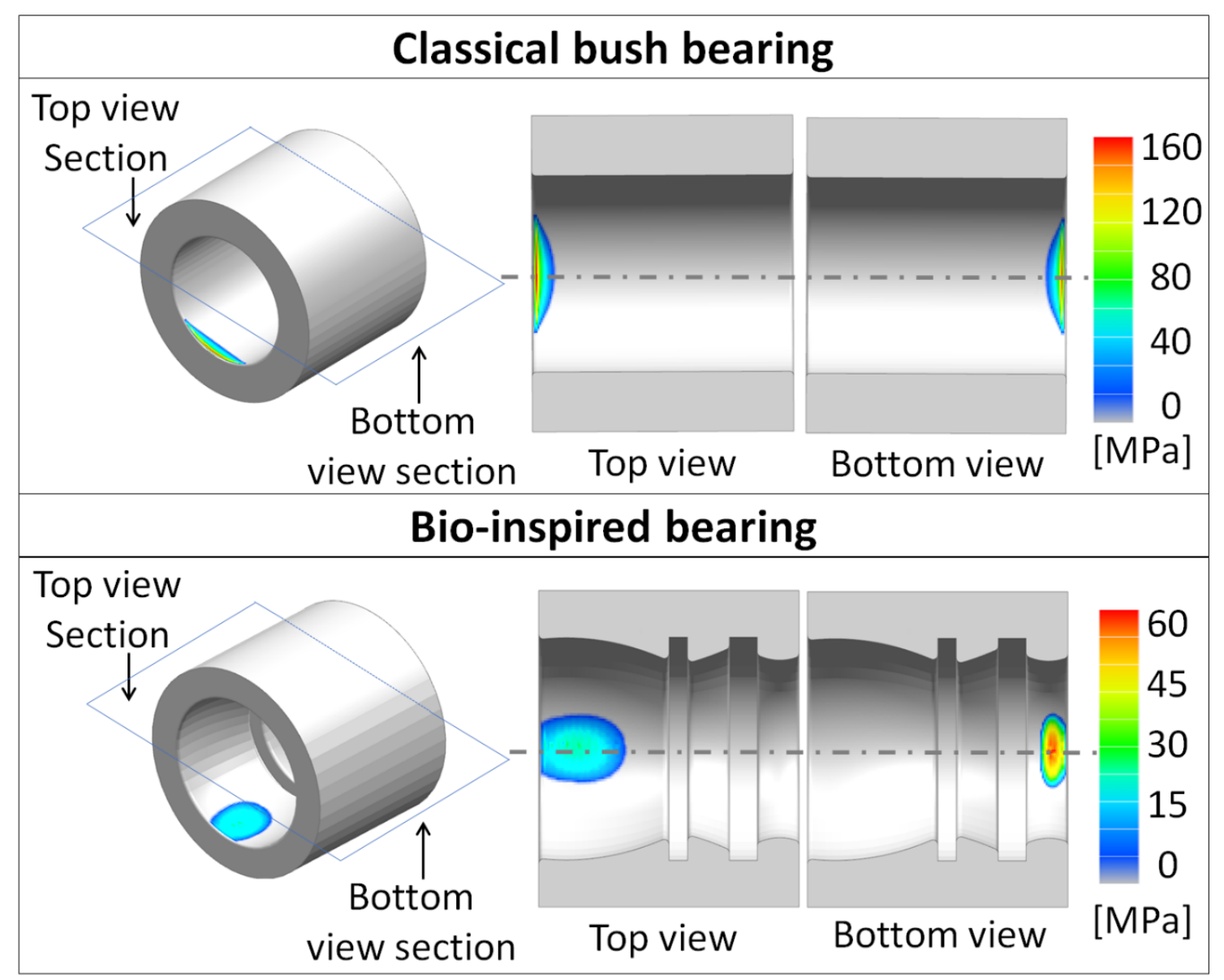

Fig. 3: Comparison of contact pressure distribution for static case study 


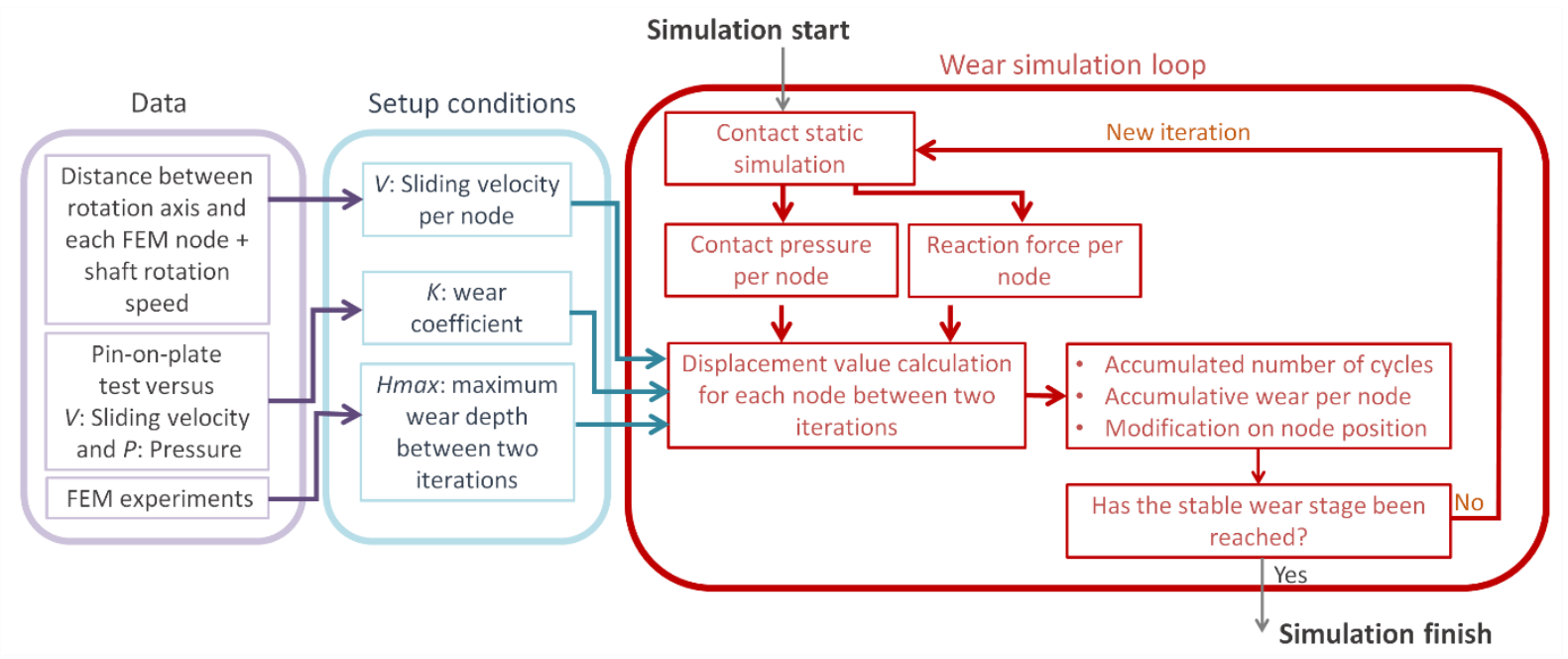

Fig. 4: Workflow of wear simulation method 


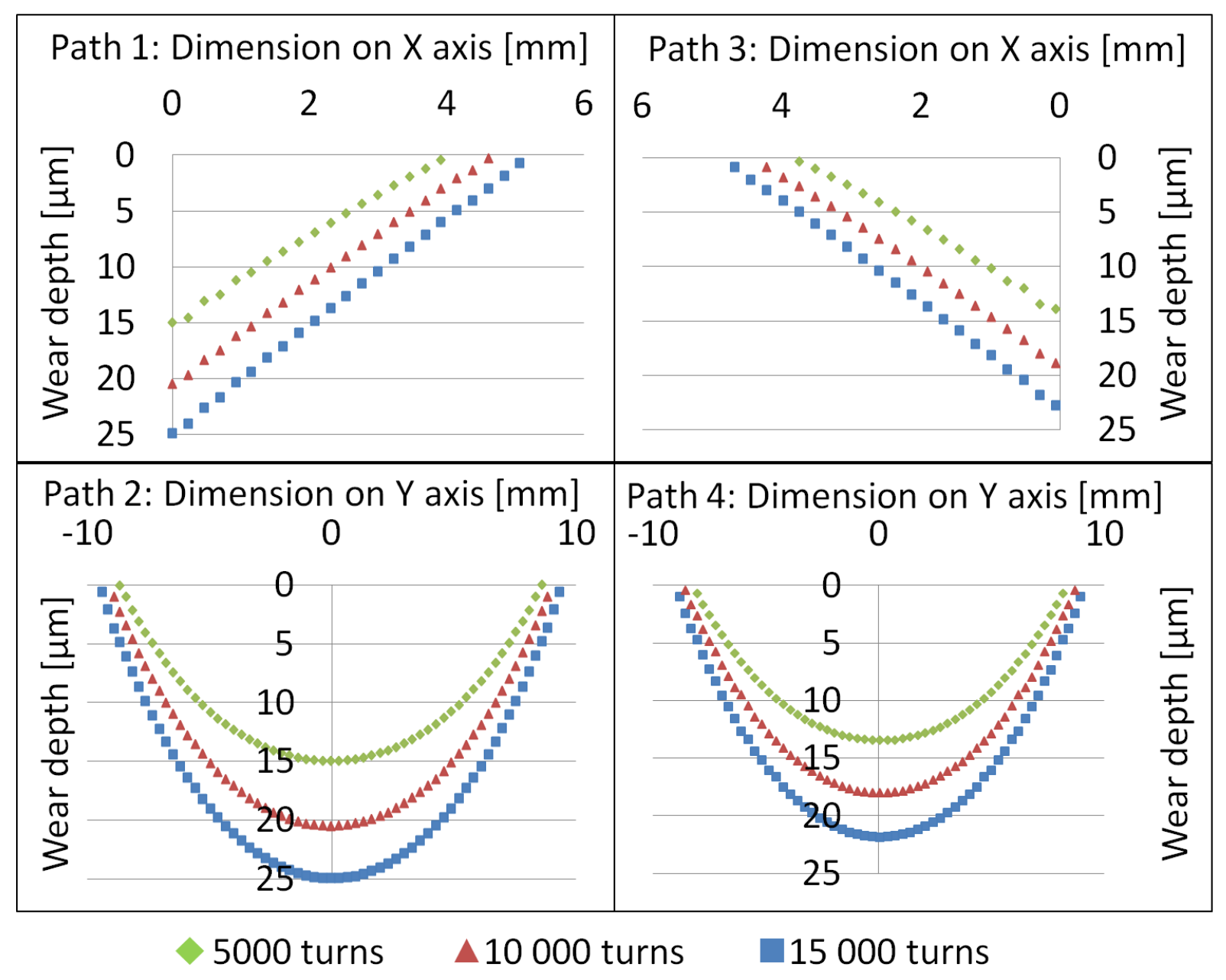

Fig. 5: Wear depth evolution along $X$ and $Y$-axes, for different steps, on classical bush bearing 


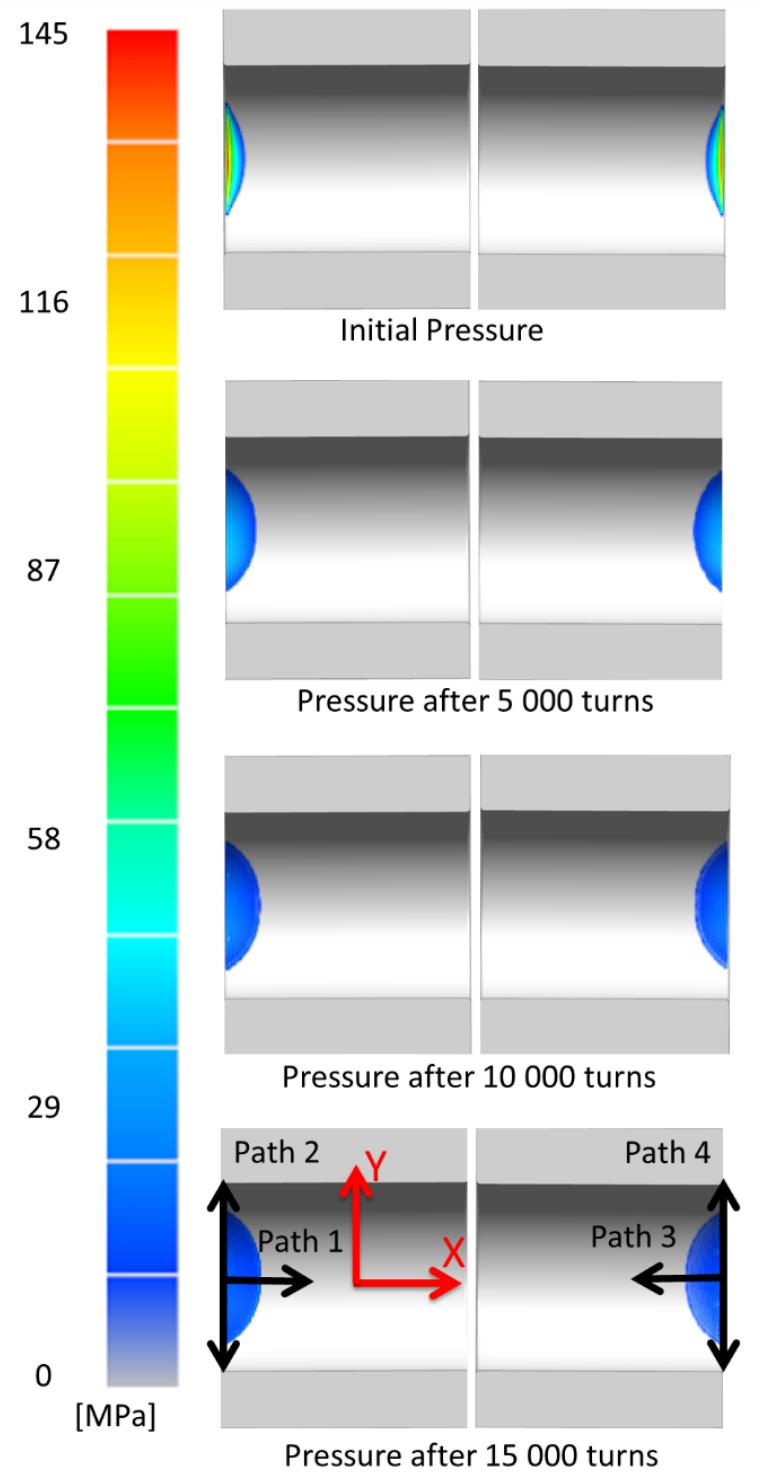

Fig. 6: Contact pressure distribution growth for different steps on classical bush bearing and definition of paths 


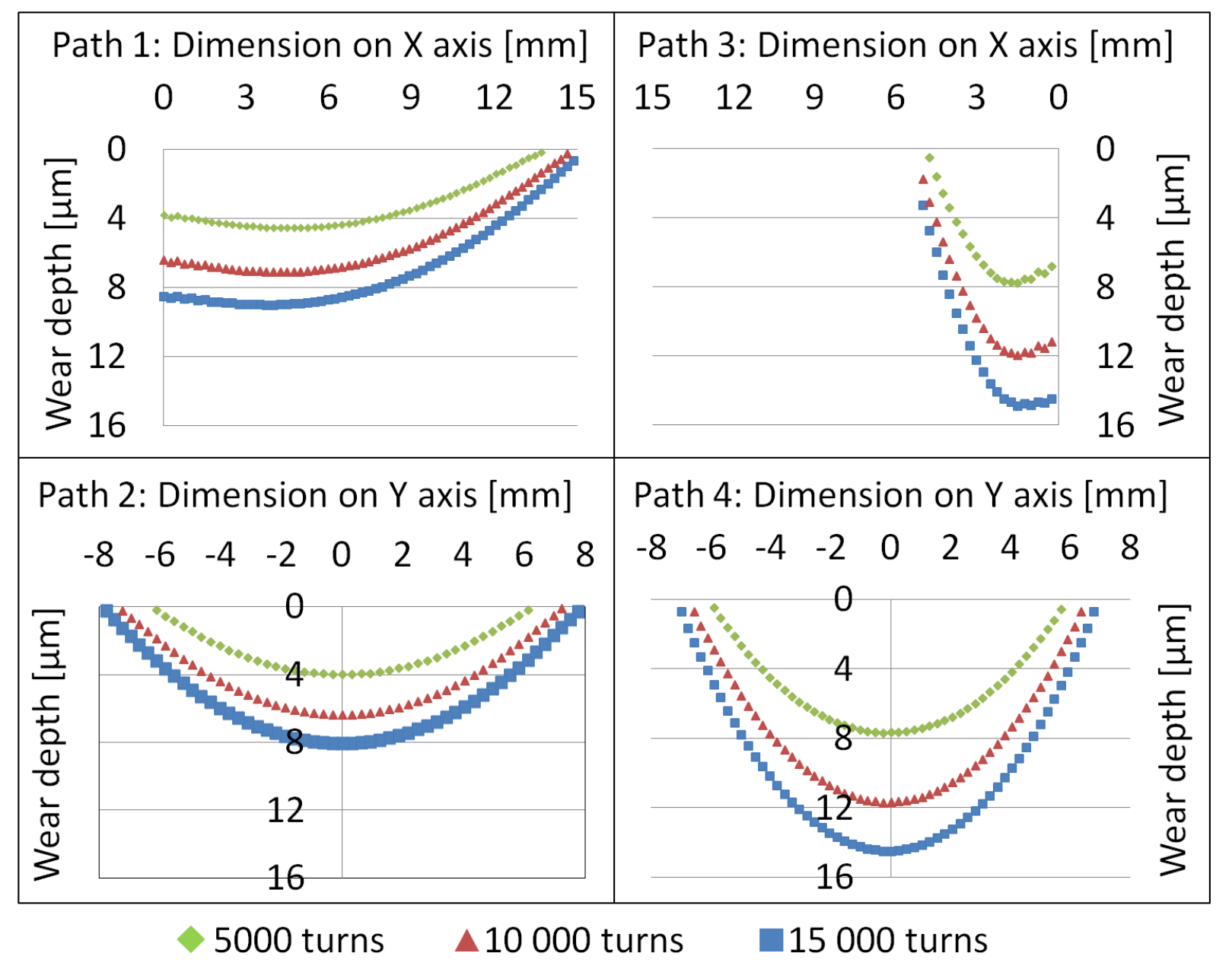

Fig. 7: Wear depth evolution along $\mathrm{X}$ and $\mathrm{Y}$-axes, for different steps, on bio-inspired bearing 


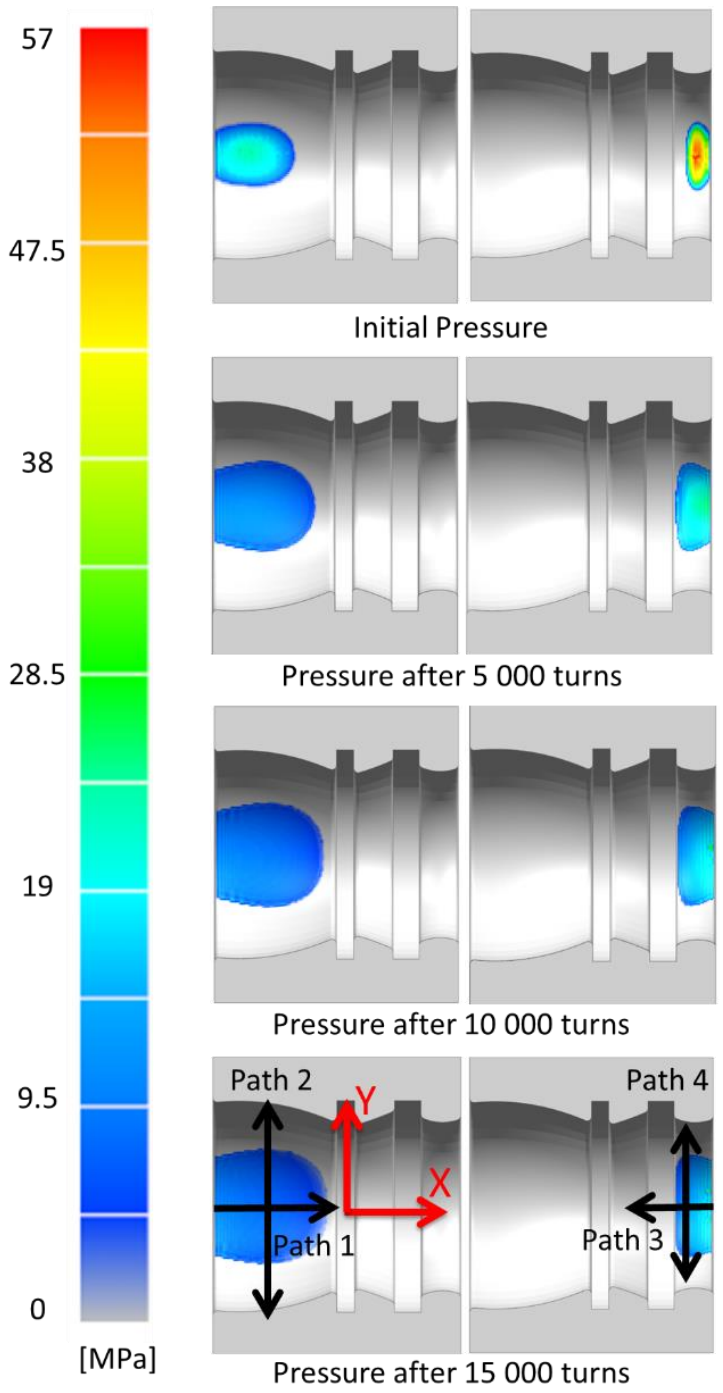

Fig. 8: Contact pressure distribution evolution for different steps on bio-inspired bearing and definition of paths 

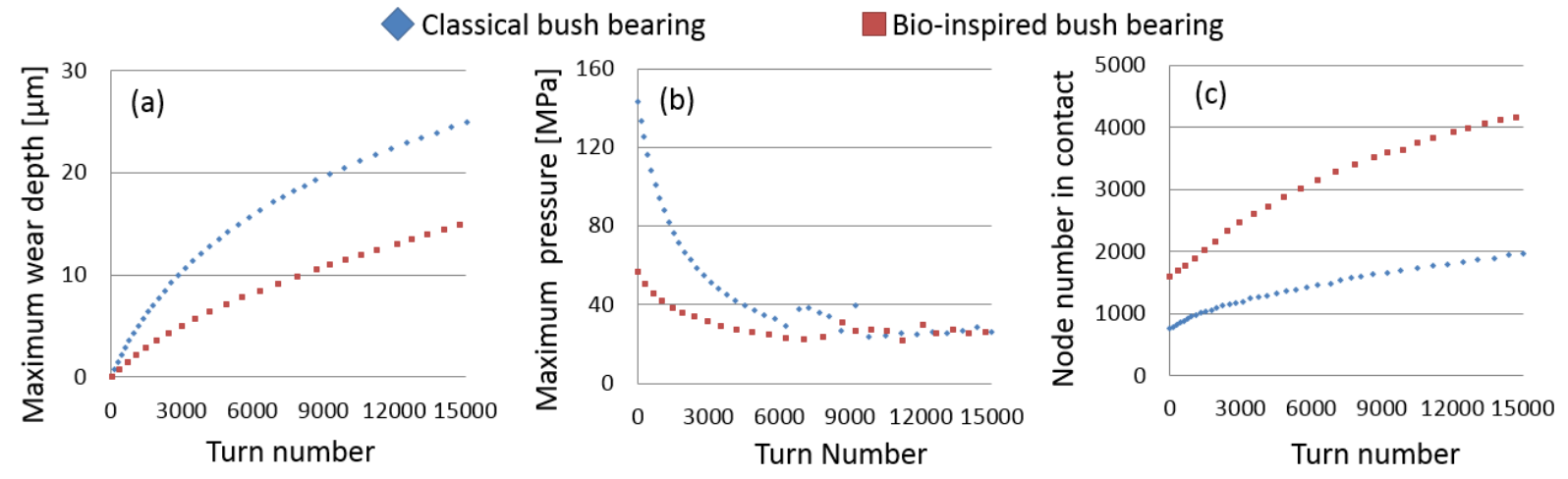

Fig. 9: For both bearings (a) Maximum wear depth per turn, (b) Maximum pressure per turn, (b) Node number in contact per tern 


\begin{tabular}{ccccc}
\hline $\begin{array}{c}\text { Test } \\
\text { Number }\end{array}$ & $\begin{array}{c}\text { Pressure } \\
(\mathrm{MPa})\end{array}$ & $\begin{array}{c}\text { Corresponding } \\
\text { Loading }(\mathrm{N})\end{array}$ & $\begin{array}{c}\text { Sliding velocity } \\
(\mathrm{mm} / \mathrm{min})\end{array}$ & $\begin{array}{c}\text { Wear coefficient } \\
\left(\mathrm{mm}^{2} / \mathrm{N}\right)\end{array}$ \\
\hline 1 & 50 & 30 & 7200 & $2.96 \mathrm{E}-10$ \\
2 & 55 & 38 & 7200 & $1.14 \mathrm{E}-9$ \\
3 & 60 & 52 & 7200 & $5.42 \mathrm{E}-10$ \\
4 & 50 & 30 & 8160 & $7.99 \mathrm{E}-10$ \\
5 & 55 & 38 & 8160 & $1.34 \mathrm{E}-9$ \\
6 & 60 & 52 & 8160 & $1.48 \mathrm{E}-10$ \\
7 & 50 & 30 & 9210 & $2.75 \mathrm{E}-10$ \\
8 & 55 & 38 & 9210 & $5.45 \mathrm{E}-10$ \\
9 & 60 & 52 & 9210 & $1.42 \mathrm{E}-10$ \\
\hline
\end{tabular}

Table 1: Different tests for wear coefficient determination 


\section{Figure Captions List}

Fig. 1 Bio-inspiration processes. (a) Off-center load on the lamb elbow (b) Lamb elbow (c) Humerus cartilage (d) Radius cartilage (e) Bio-inspired bearing

Fig. 2 Bio-inspired and classical bearings dimensions

Fig. 3 Comparison of contact pressure distribution for static case study

Fig. $4 \quad$ Workflow of wear simulation method

Fig. 5 Wear depth evolution along $\mathrm{X}$ and $\mathrm{Y}$-axes, for different steps, on classical bush bearing

Fig. 6 Contact pressure distribution growth for different steps on classical bush bearing and definition of paths

Fig. 7 Wear depth evolution along $\mathrm{X}$ and $\mathrm{Y}$-axes, for different steps, on bioinspired bearing

Fig. 8 Contact pressure distribution evolution for different steps on bio-inspired bearing and definition of paths

Fig. 9 Definition of paths on bio-inspired bearing 


\section{Table Caption List}

Table 1 Different tests for wear coefficient determination

E-mail: delphine.sysaykeo@etu.univ-amu.fr 